\title{
DEMOCRACIA NA PERIFERIA: RECEITAS DE REVITALIZAÇÃO DEMOCRÁTICA À LUZ DA REALIDADE BRASILEIRA
}

\author{
Luís Felipe Miguel \\ Professor de Ciência Política da Universidade de Brasília \\ E-mail: Ifelipe@unb.br
}

\section{Resumo}

A expansão da democracia eleitoral, que, ao menos no Ocidente, se converteu virtualmente no único regime político capaz de angariar legitimidade, não significou a resolução de seus problemas. Embora a idéia de "governo do povo" receba adesão quase universal, as instituições representativas são alvo de descrédito crescente, que se manifesta em alto absenteísmo eleitoral, desgaste dos partidos políticos e sentimento de impotência do cidadão comum. Os países que se situam à margem dos centros do capitalismo mundial, como o Brasil, enfrentam problemas adicionais. Temos uma democracia jovem, carente de "consolidação", que sofre o duro teste da eficácia de suas políticas econômicas e sociais, num quadro internacional em que o espaço de ação dos Estados nacionais, em especial na periferia, parece ter-se reduzido. Este trabalho busca reler parte das propostas recentes para a revitalização da prática democrática (deliberacionistas, comunitaristas e outras), observando os obstáculos que condições políticas, econômicas e sociais de países como o Brasil colocam à efetivação de alternativas pensadas a partir da realidade do mundo desenvolvido.

Palavra-chave: teoria democracia; democracia participativa; orçamento participativo 
ste artigo apresenta as primeiras idéias de um projeto de pesquisa que ainda está em fase de esboço. Ele parte de uma insatisfação que acredito ser compartilhada por muitos cientistas sociais brasileiros, latino-americanos ou, de maneira mais geral, periféricos: a insatisfação com a posição de "consumidores de modelos", à qual parecemos condenados pela divisão internacional do trabalho intelectual ${ }^{1}$. A transferência dos modelos - pensados a partir de realidades muito diferentes, mas logo apresentados como tendo alcance universal - não está isenta de problemas. Isso não quer dizer que as teorias importadas não possam ser úteis para compreender a realidade brasileira, o que representaria um nativismo ingênuo e injustificável. Quer dizer, isto $\operatorname{sim}$, que a importação coloca problemas específicos, que precisam ser enfrentados, sob pena de não sermos capazes de entender nossa própria realidade (e, portanto, não sabermos como transformá-la).

O problema que me ocupa aqui é o da teoria da democracia. Nas últimas duas décadas, a democracia liberal experimentou um triunfo quase universal. Argumentos que sustentavam a ausência de instituições democrático-liberais em muitos países do mundo - sua inadequação às necessidades da superação do subdesenvolvimento ou, então, diferenças de tradições culturais, com o recurso preferencial a formas comunitárias ancestrais de gestão do poder - foram descartados como meras derivações destinadas a perpetuar regimes autoritários ou oligárquicos (o que, aliás, era em geral correto). No entanto, a expansão da democracia foi acompanhada de sintomas de crise, até mesmo nos países centrais.

A palavra "democracia" carrega consigo dois níveis de significado (no mínimo). Ela é o "governo do povo", segundo seu significado etimológico, herdando da Antiguidade grega todo um imaginário que continua presente até hoje, quer na linguagem

\footnotetext{
${ }^{1}$ Um exemplo de rebeldia contra esta posição - independente das ressalvas que possam ser feitas quanto ao resultado final - é o colossal projeto de pesquisa dirigido por Boaventura de Sousa Santos, intitulado "Reinventar a emancipação social: para novos manifestos", e com a participação de autores de Portugal, Brasil, Moçambique, Colômbia, África do Sul e Índia. Os dois primeiros volumes, de sete projetados, já foram lançados (SANTOS, 2002a, 2002b).
} 
constitucional ("todo o poder emana do povo"), quer no discurso político, quer - o que é mais importante - numa percepção normativa difundida na sociedade. Por outro lado, a democracia designa um conjunto de regras e instituições, a maior parte de caráter liberal (direitos individuais, instituições representativas), cujo elemento especificamente democrático só o é de forma ambígua: o sufrágio universal, democrático no pólo do eleitorado, mas aristocrático, ou seja, seletivo, no pólo dos escolhidos (MANIN, 1997, p.149).

Tal ambigüidade desempenha um papel nada desprezível na democracia liberal, já que o apelo normativo do "governo do povo" contribui para a legitimação de sistemas políticos nos quais está manifesto que o povo não governa. No entanto, evidências recentes demonstram a emergência do que a literatura chamou de "cidadãos críticos": uma massa crescente de pessoas que expressa profunda desconfiança em relação às instituições representativas e aos poderes constitucionais, mas que nem por isso adere a valores autoritários. Pelo contrário, permanece uma forte vinculação ao ideal democrático, que é o "metro" em confronto com o qual o desempenho das instituições é (mal) avaliado. Os elementos que sustentam tal afirmação incluem surveys em inúmeros países e o declínio, mais ou menos generalizado, do comparecimento eleitoral (NORRIS, 1999; MIGUEL, 2003).

Não cabe discutir aqui se o aparente "paradoxo democrático", como colocou Robert Dahl (2000), em forma interrogativa, num artigo influente, é mesmo paradoxal ou apenas uma demonstração de realismo dos cidadãos diante do enorme fosso entre o ideal e sua pretensa efetivação. O que importa é assinalar que, a partir desta situação, dois caminhos principais se abrem para a teoria democrática. Uma corrente "realista", de matriz schumpeteriana, assume que a melhor aproximação possível da democracia é a "oligarquia eleitoral" que nós temos - para usar a expressão de Pierre Vidal-Naquet (2002, p.14) - e contenta-se com ela. Embora Samuel Huntington (1994, p.16) tenha-se apressado a afirmar que a posição schumpeteriana afirmou-se vitoriosa, nos anos 1970, encerrando o debate no seio da teoria democrática, uma análise da literatura contemporânea desmente tal conclusão. É exatamente a partir da década de 1970, junto com a emergência da cidadania crítica, que florescem as principais vertentes de um segundo caminho da teoria 
democrática: a que se estabelece a partir da crítica às democracias realmente existentes, procura extrair uma essência não realizada do conceito de democracia e postula, então, um conjunto de propostas para o revigoramento das práticas democráticas.

Não é tarefa fácil produzir uma taxionomia das diversas correntes da teoria democrática, nem mesmo de suas tendências radicais - que, aliás, mantêm uma rede intrincada de relações e contaminações entre si e também com as tendências liberais hegemônicas. Com todas as ressalvas que um empreendimento do tipo merece, creio ser razoável apresentar três grandes categorias de democracia radical. Todas elas buscam religar a democracia contemporânea com o ideal democrático e (implícita ou explicitamente) com seu modelo histórico, a cidade grega. Mas cada uma tende a privilegiar um aspecto diverso do ideal e do modelo histórico. As três categorias são:

(1) a democracia participativa, que destaca a participação efetiva dos cidadãos na tomada de decisões como sendo o traço distintivo de um ordenamento genuinamente democrático. Os principais textos da corrente, que inclui autores como Carole Pateman e C. B. Macpherson, foram produzidos nos anos 1970. Os participacionistas julgavam necessárias instituições democráticas ao nível da vida quotidiana, sobretudo nos locais de trabalho (a chamada "democracia industrial", que exigia formas de autogestão). Com isso, haveria tanto uma ampliação significativa do controle dos cidadãos sobre a própria vida quanto a ampliação de seu entendimento sobre o funcionamento da política e da sociedade, o que deveria permitir uma maior capacidade de interlocução com e fiscalização de seus representantes. Isto é, a accountability (responsividade do representante perante os representados), que na democracia eleitoral tende a funcionar precariamente, seria aprimorada com o treinamento oferecido pela participação na base. A compreensão deste vínculo entre os níveis micro e macro, que recupera o caráter educativo da atividade política apontado por pensadores como Rousseau e Stuart Mill, é 
essencial para que o modelo participativo ganhe sentido. A corrente participacionista faz uma aposta, talvez excessiva, na disposição das pessoas para o envolvimento político, julgando que a apatia presente é efeito apenas da ausência de oportunidades e do desestímulo estrutural. Estudos sobre processos de tomada de decisão em nível local revelaram certas desfuncionalidades, bem como a permanência de desigualdades, que a teoria em geral ignorava (MANSBRIDGE, 1983). E o entusiasmo com experiências de autogestão, em especial as que ocorriam na antiga Iugoslávia, recuou à medida que se obtiveram dados mais acurados sobre seu real funcionamento (PATEMAN, 1989).

(2) a democracia republicana, que exalta a virtude cívica - o sentimento da vinculação com a comunidade, que faz com que a busca do bem comum se sobreponha ao interesse particular - e se opõe ao individualismo exacerbado da corrente liberal. Mais do que a participação em si, o importante é o vínculo comunitário. ( $\mathrm{O}$ amálgama entre republicanismo cívico e comunitarismo, que faço aqui, não está isento de arestas; para os fins da presente discussão, porém, ele é sustentável.) Os teóricos da corrente precisam estabelecer um equilíbrio delicado entre o valor da liberdade individual, do qual poucos estariam dispostos a abrir mão, e a preservação da coletividade ${ }^{2}$. Em certa medida, a corrente floresceu como reação ao Estado de bem-estar social, que substituía a interação local, marcada pela solidariedade "quente" entre os integrantes de uma mesma comunidade, pela rede "fria" de proteção do Estado, efetivada por burocratas e profissionais distantes de seu público;

(3) a democracia deliberativa, inspirada sobretudo nas obras de Habermas sobre a esfera pública e sobre a ação

${ }^{2}$ As tensões entre estes dois pólos são bem perceptíveis, por exemplo, na obra de Michael J. Sandel (1998), que bem pode ser considerado o principal teórico comunitarista. 
comunicativa (mas também na teoria de Rawls). O traço definidor da democracia passa a ser o debate de idéias, cujo resultado almejado, ainda que nem sempre alcançado, é o consenso. Sob este ponto de vista, o principal problema das democracias eleitorais contemporâneas não é tanto o déficit de participação ou a decadência da virtude cívica - se bem que os ideais de participação e de bem comum não sejam estranhos à vertente deliberacionista - quanto o esvaziamento da esfera pública discursiva. A política se torna, assim, um instrumento para a consecução de objetivos privados, sem espaço para o debate racional.

Feita esta categorização, muito sumária, das vertentes críticas da teoria democrática, é possível agora aproximar seus receituários da realidade brasileira. Por caprichos da argumentação, será seguida a ordem inversa; isto é, primeiro a discussão sobre a democracia deliberativa, depois sobre a republicana e, por fim, sobre a participativa.

Na definição de um de seus principais autores, Joshua Cohen (1998, p.186), a democracia deliberativa julga que as decisões públicas devem ser tomadas por aqueles que estarão submetidos a elas, através do "raciocínio público livre entre iguais". Privilégio ao argumento racional, liberdade e igualdade são também características da "situação de fala ideal" projetada por Habermas; sua quarta faceta é a busca do consenso entre os participantes. Não é possível revisar aqui toda a vasta literatura sobre o deliberacionismo, que vai matizar e reformar muitos de seus pressupostos. Basta assinalar que todas as quatro características foram submetidas à pesada crítica, sendo apontadas como utópicas e incapazes de apreender a dinâmica da política enquanto espaço de manifestação de conflitos de interesses sociais.

Para os fins da presente discussão, basta observar como quatro problemas centrais da proposta deliberacionista se tornam ainda mais graves num cenário de desigualdade econômica e social tão profunda quanto o brasileiro. Críticos da teoria deliberativa apontam que "as competências necessárias à participação no debate público estão desigualmente distribuídas" e que, portanto, aqueles setores sociais que não desenvolveram as ferramentas cognitivas e argumentativas adequadas 
estarão prejudicados de forma sistemática ${ }^{3}$. De fato, sem enfrentar esta questão o deliberacionismo cai no mesmo problema do liberalismo, isto é, o descompasso entre o direito formal de acesso à esfera pública (discursiva, no caso) e a capacidade de intervenção efetiva nela.

No caso do Brasil, o problema é agravado pela precariedade da escola. Boa parte de nossa população simplesmente não teve acesso, ou teve um acesso muito superficial, aos códigos que tornam possível a participação no debate público racional. Afinal, embora a razão seja atributo de todos os seres humanos, a produção de um "argumento racional" exige a obediência a determinadas regras. Em suma, a nossa realidade coloca, com uma urgência muito maior, o problema das "condições materiais" para a efetivação da esfera pública, com a distribuição de um kit de ferramentas cognitivas e discursivas básicas a todos os grupos sociais. Mesmo nos países desenvolvidos, é discutível a postura - comum a muitos deliberacionistas - de legar este problema às notas de rodapé. Para os países periféricos, não é admissível sequer cogitar tal estratégia.

O segundo problema está ligado ao "controle dos meios de comunicação de massa". A não ser no elevado nível de abstração em que trabalham muitos teóricos deliberacionistas, o que torna suas reflexões pouco úteis para compreender e transformar a realidade, não é possível ignorar que o debate público se efetiva na mídia; portanto, é fundamental discutir quem controla os conteúdos que ela transmite (MIGUEL, 2000). A concentração da propriedade da mídia nas mãos de uns poucos grupos é um fenômeno mundial, com consequiências graves para a democracia (BAGDIKLAN, 1997; McCHESNEY, 1999). Mais ainda no Brasil, um país que saltou da cultura oral para a cultura eletrônica, sem passar efetivamente pela etapa da escrita; um país em que a instituição escolar pouco tem a oferecer como contrapartida às mensagens veiculadas na mídia. Isto torna os meios de comunicação eletrônicos ainda mais estratégicos na condução do debate público. Além disso, outros fatores agravam o quadro, no caso brasileiro: a

\footnotetext{
${ }^{3}$ A crítica é levada a cabo, entre outros, por Iris Marion Young, Lynn Sanders e Pierre Bourdieu. Entre os principais teóricos deliberacionistas, o ponto é discutido sobretudo por James Bohman (1996, p.112-25).
} 
fraca concorrência no âmbito da mídia dominante, a televisão; a debilidade do setor de mídia não-comercial; a frouxidão dos códigos profissionais que permitiriam alguma resistência por parte dos jornalistas, diante das pressões dos controladores das empresas.

A existência de "interesses sociais irreconciliáveis" é o terceiro problema, grave nos países centrais, mas talvez ainda mais grave na periferia, onde as desigualdades são mais profundas. Bem ou mal, durante boa parte do século passado, a Europa ocidental vivenciou um acordo de convivência entre capital e trabalho, na forma do Estado de bem-estar. Nada de semelhante jamais existiu no Brasil, onde a exploração do trabalho é feroz e cerca de um quinto da população vive em situação de penúria extrema. A busca do "consenso" entre as massas excluídas e a minoria privilegiada, como exigiria uma abordagem deliberacionista levada ao pé da letra, soa como piada de mau gosto. Em suma, quando o que está em jogo são as condições mínimas de subsistência, não há conciliação possível para o conflito de interesses.

Estreitamente ligado ao anterior, o último problema diz respeito à premência das decisões políticas, em face de condições extremas de desigualdade e pobreza. Isto é evidente no caso da exigência de consenso, que paralisa a ação política, preservando o status quo. Uma ilustração prototípica de medida destinada a gerar consenso está na definição do "ótimo de Pareto" (situação em que ninguém é prejudicado e pelo menos um indivíduo recebe algum benefício). Medidas que buscam reduzir desigualdades sociais dificilmente cumprem tais requisitos. O consenso, tende, portanto, ao conservadorismo.

Mas a própria deliberação, com seu tempo para argumentação, contra-argumentação e reflexão, também pode ser paralisante e protelatória, conforme demonstrou Iris Marion Young num artigo esclarecedor. Por exemplo, convites para que representantes de movimentos sociais participem de fóruns deliberativos implicam na legitimação de instituições injustas, levam à desmobilização e ao abandono de formas de intervenção mais eficazes e são, muitas vezes, uma via de cooptação. Na verdade, o ativismo político - que foi, historicamente, o principal meio de promoção dos interesses dos grupos dominados - com frequiência exige a interrupção do processo deliberativo e a adoção de medidas imediatas (YOUNG, 2001). 
Enfim, as condições de país periférico reforçam a observação que Elster (1997, p.18) já fazia: "Se, como Habermas sugere, a discussão livre e racional [e igualitária, acréscimo meu] só será possível numa sociedade que tenha abolido a dominação política e econômica, não é óbvio, de maneira nenhuma, que esta abolição possa ser provocada pela argumentação racional". Na ausência das condições ideais, a teoria deliberacionista pouco nos oferece.

Tanto quanto a teoria deliberacionista, a democracia republicana se situa, em primeiro lugar, no plano normativo. A política "deve" perseguir o bem comum, o que ecoa o Maquiavel dos Discorsi, herói indiscutido da corrente. O Maquiavel d'O príncipe, por sua vez, nos lembra constantemente daquilo que a política "é". Mesmo sob risco de simplificação excessiva, é possível dizer que a ponte que uniria os dois extremos - da realidade ao dever ser - seria o reavivamento do sentido de comunidade, com a reafirmação dos laços de solidariedade e identidade que ligam o indivíduo a seu grupo.

O caráter potencialmente conservador que assume a crítica comunitarista ao liberalismo - com maior clareza nas mãos de autores menos sofisticados, como Christopher Lasch - já foi sobejamente apontado. $\mathrm{O}$ confronto com a realidade brasileira ajuda a indicar dois pontos principais. Primeiro, que, na ausência de intervenção corretiva do Estado, a comunidade pode ser um viveiro da desigualdade e da precariedade das condições materiais. O resultado é, muitas vezes, a tutela da comunidade por um "poderoso", como revelam os esquemas políticos clientelistas e neoclientelistas.

Em segundo lugar, fica claro que a crítica do Estado de bemestar social exige antes a existência de um estudo. Não há dúvida de que a intervenção estatal permanente desorganiza redes comunitárias, induz à passividade, faz com que o sentimento de responsabilidade mútua, que existe entre pessoas que vivem em comum, seja substituído pela dependência em relação à instituição protetora. Aliás, tudo isso já está em Tocqueville. Mas será que a "comunidade" é a solução? A interação "quente" entre mulheres das favelas brasileiras, que cuidam dos filhos umas das outras devido à ausência de atendimento préescolar, pode ser vista simpaticamente como demonstração de solidariedade comunitária. Mas não seria melhor garantir a todas o 
atendimento "frio" proporcionado por uma creche sustentada pelo Estado e operada por seus funcionários? Aliás, o exemplo mostra também que a crítica ao Estado de bem-estar, que não é exclusividade dos comunitaristas, possui um viés de gênero: ela costuma ignorar o fato de que o peso da "solidariedade comunitária" recai quase todo sobre as mulheres (FRASER, 1989).

Tanto a democracia deliberativa quanto a republicana fracassam em entender a centralidade dos problemas materiais na construção da ordem democrática - um aspecto que, sem dúvida, enfraquece sua utilidade nos países centrais, mas que, no Terceiro Mundo, representa uma inadequação ainda maior. A corrente participacionista sempre focou com mais atenção a relação entre desigualdade material e política. Não por acaso, ela vai ter um impacto maior no debate político brasileiro, inspirando aquele que é considerado o principal experimento para o aperfeiçoamento democrático no país: o chamado "orçamento participativo", marca de diversos governos municipais e estaduais de esquerda, sobretudo ligados ao Partido dos Trabalhadores, desde o final da década de 1980.

A literatura sobre o orçamento participativo é vasta, crescente e costuma assumir um tom apologético. Abers (2000, p.4), que estuda a experiência de Porto Alegre, afirma que a capital gaúcha promoveu a "revitalização da vida cívica", tornou a distribuição de recursos públicos "mais transparente e accountable para a cidadania", favoreceu e "empoderou" os pobres em lugar dos ricos e transformou-se num "local vibrante de organização e ativismo". Avritzer (2002, p.19) é mais preocupado em apreender possíveis desfuncionalidades, mas não deixa de ecoar o senso comum quando classifica o orçamento participativo como a "mais inovadora prática de gestão democrática em nível local"4. Baierle (2000, p.212) julga que ele gera uma "ética democrática radical". Os efeitos positivos sobre a cultura política, a gestão do Estado e a autonomia popular também são destacados por Santos (2002c).

Não se trata de negar a importância das experiências de orçamento participativo na renovação de práticas políticas locais, na ruptura com esquemas clientelistas cristalizados e na abertura das

${ }^{4}$ Em outro texto, ele o apresenta como efetivação da democracia deliberativa (AVRITZER, 2000, p.43). 
instâncias decisórias aos movimentos populares urbanos. Mas é necessário perceber que o orçamento participativo não é capaz de nos dar tudo o que seus apologetas pretendem extrair dele. Em especial, para a presente discussão, é importante perceber que o orçamento participativo não é um instrumento de democracia participativa.

Vale analisar aqui, ainda que brevemente, o sentido da "participação política". Por um lado, qualquer forma de engajamento com a esfera política é uma participação; é a percepção que orienta a construção de "índices de participação", que passam pelo voto, pela presença em comícios, pela contribuição financeira a partidos e candidatos, pela discussão de temas políticos com amigos. Quando apresenta seu modelo de democratização, Dahl indica a "participação" com uma das dimensões relevantes, mas o termo, para ele, indica apenas a expansão do direito de voto. A "participação" pregada pelos teóricos da democracia participativa, porém, está vinculada a um sentido mais forte da palavra. Ela significa o acesso a locais de tomada final de decisão; isto é, implica na transferência de alguma capacidade decisória efetiva do topo para a base. Parte importante das decisões ainda seria tomada por delegados eleitos, é claro; mas a teoria supõe que a experiência na gestão direta de poder na base ampliará a capacidade de compreensão sobre a política mais geral e de escolha dos representantes.

Fica claro que a participação do orçamento participativo está muito mais ligada ao sentido fraco do que ao sentido forte da palavra. Embora ocorram variações de local para local e ao longo do tempo, ele é tipicamente uma estrutura delegativa piramidal. Todos os moradores têm a possibilidade de participar das discussões em assembléias de base (se bem que apenas uma minoria o faça), que culminam com a eleição de uma lista de prioridades e de um número de delegados. Tais delegados se encontram e escolhem outros, num processo que termina por produzir um "conselho", com poderes para negociar, amalgamar e substituir as prioridades votadas. É o conselho quem, no final das contas, produz a proposta orçamentária - na verdade, um adendo a uma proposta orçamentária, já que o grosso dos recursos públicos pertence a rubricas fixas e não passa pelo conselho de representantes da base.

Em todo o processo, a participação popular consiste sobretudo na escolha de delegados; neste sentido, não é qualitativamente diferente 
da participação eleitoral. As experiências de orçamento participativo promovem, portanto, uma duplicação de instâncias representativas, sem a transferência de poder decisório real para os cidadãos comuns. E tratase de uma representação complexa, em vários níveis, não apenas pela estrutura piramidal de escolha de delegados, mas porque é necessário entender os participantes das assembléias de base como representantes da população mais ampla, que na sua maioria não comparece ${ }^{5}$.

Não cabe aqui discutir os limites e potencialidades destas experiências para o aprofundamento das práticas democráticas. O que importa é perceber que, entendido desta forma, o foco da discussão sobre o próprio orçamento participativo muda. Seu aprimoramento passa a depender do melhor funcionamento dos mecanismos de accountability, ligando os representantes aos representados, nos diferentes níveis em que tal participação se dá.

Ao mesmo tempo, a definição do orçamento participativo como forma de política representativa recoloca a democracia participativa em seus devidos termos. À medida que engloba necessariamente a transferência de capacidade decisória para os cidadãos comuns dentro dos espaços da vida cotidiana, ela não tem como se esquivar do problema da reorganização das relações de produção. Isto é, um ordenamento democrático participativo é incompatível com a manutenção do capitalismo, fato reconhecido mesmo por liberais esclarecidos como Robert Dahl (1989).

Com todas as limitações que possui - e que, em grande medida, os próprios autores da corrente identificaram -, a vertente participacionista toca em pontos cruciais, estabelecendo a ligação necessária entre as instituições políticas e o mundo material. Por isso, parece ser uma ferramenta mais útil para pensar as possibilidades (e os limites) do aprofundamento das democracias, nos países centrais e também na periferia. No entanto, a principal apropriação que no Brasil tem sido feita do participacionismo, que o reduz a assembléias orçamentárias e a outras arenas paraestatais, deixa de lado exatamente o que ele possui de mais rico e de mais estimulante.

${ }^{5}$ Um esboço de sustentação teórica para a compreensão da relação entre presentes e ausentes como sendo uma relação de representação é dado por Mansbridge (1983, p.248-51). 


\section{Referências}

ABERS, Rebecca Neaera. Inventing local democracy: grassroots politics in Brazil. Boulder: Lynne Rienner, 2000.

AVRITZER, Leonardo. O orçamento participativo: as experiências de Porto Alegre e Belo Horizonte. In: DAGNINO, Evelina (Org.). Sociedade civil e espaços públicos no Brasil. São Paulo: Paz e Terra, 2002.

Teoria democrática e deliberação pública. Lua Nova, São Paulo, n.50, p. $25-46,2000$.

BAGDIKIAN, Ben H. The media monopoly. 5.ed. Boston: Beacon Press, 1997.

BAIERLE, Sérgio Gregório. A explosão da experiência: emergência de um novo princípio ético-político nos movimentos populares urbanos em Porto Alegre. In: ALVAREZ, Sonia; DAGNINO, Evelina; ESCOBAR, Arturo (Orgs.). Cultura e política nos movimentos sociais latino-americanos: novas leituras. Belo Horizonte: Ed. UFMG, 2000.

BOHMAN, James. Public deliberation: pluralism, complexity, and democracy. Cambridge: MIT Press, 1996.

COHEN, Joshua. Democracy and liberty. In: ELSTER, Jon (Ed.). Deliberative democracy. Cambridge: Cambridge University Press, 1998.

DAHL, Robert A. Um prefácio à democracia econômica. Rio de Janeiro: Jorge Zahar, 1989.

A democratic paradox?" Political Science Quaterly, New York, v.115, n. 1, p.35-40, 2000.

ELSTER, Jon. The market and the forum: three varieties of political theory. In: BOHMAN, James; REHG, William (Eds.). Deliberative democracy: essays on reason and politics. Cambridge: MIT Press, 1997.

FRASER, Nancy. What's critical about critical theory? The case of Habermas and gender. In: . Unruly practices: poer, discourse and gender in contemporary social theory. Minneapolis: University of Minnesota Press, 1989.

HUNTINGTON, Samuel P. A terceira onda: a democratização no final do século XX. São Paulo: Ática, 1994.

MANIN, Bernard. The principles of representative government. Cambridge: Cambridge University Press, 1997. 
MANSBRIDGE, Jane J. Beyond adversary democracy. Chicago: The University of Chicago Press, 1983.

McCHESNEY, Robert W. Rich media, poor democracy: communication politics in dubious times. Urbana: University of Illinois Press, 1999.

MIGUEL, Luis Felipe. Um ponto cego nas teorias da democracia: os meios de comunicação. BIB - Revista Brasileira de Informação Bibliográfica em Ciências Sociais, Rio de Janeiro, n.49, p.51-77, 2000.

Representação política em 3-D: elementos para uma teoria ampliada da representação política. Revista Brasileira de Ciências Sociais, São Paulo, n.51, 2003. No prelo.

NORRIS, Pippa (Ed.). Critical citizens: global support for democratic governance. Oxford: Oxford University Press, 1999.

PATEMAN, Carole. The civic culture: a philosophic critique. em The disorder of women. Stanford: Stanford University Press, 1989.

SANDEL, Michael J. Liberalism and the limits of justice. 2.ed. Cambridge: Cambridge University Press, 1998.

SANTOS, Boaventura de Sousa (Org.). Democratizar a democracia: os caminhos da democracia participativa. Rio de Janeiro: Civilização Brasileira, $2002 \mathrm{a}$.

Produzir para viver: os caminhos da produção não capitalista. Rio de Janeiro: Civilização Brasileira, 2002b.

Orçamento participativo em Porto Alegre: para uma democracia redistributiva. In: SANTOS, Boaventura de Souza (Org.). Democratizar a democracia: os caminhos da democracia participativa. Rio de Janeiro: Civilização Brasileira, 2002c.

VIDAL-NAQUET, Pierre. Os gregos, os historiadores, a democracia: o grande desvio. São Paulo: Companhia das Letras, 2002.

YOUNG, Iris Marion. Activist challenges to deliberative democracy. Political Theory, Thousand Oaks, v.29, n.5, p.670-90, 2001. 


\begin{abstract}
Electoral democracy had an extraordinary expansion in the last decades. In Western countries, it was converted into the only political régime able to conquest legitimacy. But most of its problems remain unresolved. The idea of "rule of the people" earns almost universal adhesion, but representative institutions are increasingly discredited. Electoral turnout is lowering, the influence of political parties was eroded and common citizens think they are impotent. Peripheral countries, like Brazil, have additional problems. Brazilian democracy is young and needs "consolidation". Its economic and social politics are being testing, in a world that apparently reduced the space of action for nation-states, especially peripheral ones. This article essays a rereading of recent proposals to revitalize democracy (deliberationism, communitarism, and others), observing the obstacles that political, economic and social conditions of countries like Brazil put to the accomplishment of alternatives thought from the reality of the developed world.
\end{abstract}

Key words: democratic theory, participative democracy; participative budget 